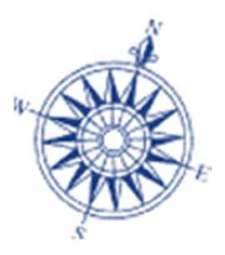

\title{
Gender gaps in educational outcomes among children of new migrants: the role of social integration from a comparative perspective.
}

\begin{tabular}{|r|l|}
\hline Journal: & Sociology Compass \\
\hline Manuscript ID: & Soco-0894 \\
\hline Wiley - Manuscript type: & Article \\
\hline Keywords: & $\begin{array}{l}\text { Political Sociology < Compass Sections, Gender < Compass Sections, Race } \\
\text { \& Ethnicity < Compass Sections }\end{array}$ \\
\hline
\end{tabular}




\title{
Gender gaps in educational outcomes among children of new migrants: the role of social integration from a comparative perspective.
}

\begin{abstract}
:
This paper reviews current research on gender gaps in educational outcomes among children of new migrants (the second generation) from a comparative cross-national perspective. While gender gaps in cognitive outcomes are shrinking in specific subjects (e.g. math and reading) and that process often seems to be more accentuated among minorities, gender gaps and disadvantages among ethnic minorities vis-à-vis other groups continue to persist in western democracies. These disadvantages vary not only across different educational systems and at different rates over time, but also based on students' social background. This article focuses on potential explanations for why gendered differences in social integration in terms of educational outcomes among immigrants (vis-à-vis non migrants) occur with special attention to micro, meso and macro level factors.
\end{abstract}

Key words: Gender gaps, educational outcomes, second generation, social integration. 


\section{Introduction}

Some scholars argue that due to the low fertility rates among native Europeans, there is a socio-political need to integrate and provide access to opportunities and advancement to children of new immigrants as these children, will be an intricate part of the sustainability and future of the welfare state systems (Alba, Sloan and Sperling 2011). In many instances, however, it is documented that the "integration imperative" does not translate into actual advancement in labor market opportunities for immigrant youth. For example, it is well known that unemployment rates among immigrant populations in some countries is twice that of the native population (i.e. Spain, Belgium and France). In other countries however, the socio-economic integration of the second generation migrant youth vis-à-vis the nonmigrant population is smoother and more homogeneous (as in the cases of Australia and Canada). In order to understand this heterogeneity across countries in migrant's socio-economic integration, the study of the trajectories of second generation migrant youth in educational systems are of critical importance (Heath et al. 2008). Moreover, their experiences often do not follow the adaptation patterns of their parents or their non-migrant peers and often manifest themselves differently across gender lines (OECD 2005). While some studies emphasize the importance of learning the language, cultural knowledge of the host society and assimilation levels among the first and second generation (Esser 2006), other studies have suggested that the process of "learning a new land" varies across gender lines and can affect their educational trajectories into the host society (Lopez 2008; Guiso et al. 2008).

The sociology of education literature has traditionally focused on how school settings play a role in helping students overcome language barriers and enable the transmission of values and norms. As such, schools are embedded in larger institutional educational environments defined by integration policies operating at the country/national level (Freeman 1995). National contexts and overall levels of social inequality thus matter in explaining individual level educational outcomes (Siddiqi et al. 2012; 
Hillmert 2013; see also Crul and Vermuelen 2003). Educational policies in conjunction with different immigration patterns (e.g. types of immigrants) result in well-institutionalized structures affecting the adaptation of first and second generation and these differences can manifest themselves across gender lines. While there is research on cross-national variation examining the relationship between the effects of national policies on educational outcomes (Siddiqi et al. 2012, see Van de Werfhorst and Mijs 2010 for a review of this literature) no research exists examining how these policies are gendered.

Indeed, cross-national studies have predominantly focused on the relationship between national educational institutions and overall inequality levels among students of various backgrounds, especially in terms of access to learning opportunities but not so much on gender differences (see Van de Werfhorst and Mijs 2010). For example, cross national comparative literature has placed significant effort in understanding the effects of educational institutional structures as they interact with other social characteristics among students, such as parental background, community involvement especially in providing explanations for achievement gaps. In spite of these strides made in the literature, there remains a void in examining gender gaps from this cross-national comparative perspective, especially as these gaps affect migrant youth. To the extent that cultural impediments exist (e.g. language barriers and cultural differences), these institutional structures, for example reliance on "tracking systems", standardization of the curriculum or existence or not of intercultural and bilingual education, may affect migrant children's differently in their patterns of assimilation across groups (e.g. first and second generation compared to natives) and across gender lines (Lopez 2003; Wolf 2006, Espiritu 2006). If these voids in the literature are to be filled, we argue that measures tapping into the actual richness (or lack thereof) of different educational policies aimed at second generation migrant youth, or what we more generally refer to as institutional educational structures, must be taken into consideration. More importantly students' individual characteristics, parental involvement, and other measures of human and social capital are to be examined in contextual models that examine institutional variation. 
The goal of this paper is to assess the literature examining the dispersion of educational cognitive outcomes and the effects of social background with a special emphasis on the intersections of gender, immigration status, ethnicity and social class and their effects on student's educational opportunities. We purport that country level differences in terms of institutional education structures may play a role, not only in explaining overall levels of achievement between and within schools, but also on gender inequality of objective outcomes (for example in actual academic performance) and in shaping students' aspirations, norms, values and attitudes towards learning (or what some scholars view as more "soft" and/or non-cognitive skills). Thus, a country with more standardization or that invests more resources towards the integration of migrant youth in educational settings and smoother transitions from school to work might set the conditions for migrant youth success. A "trickle-down" effect might exist on migrant youth and their very perceptions of success and the value of an education. Similarly other negative, trickle down effects are related to other students' characteristics (race, gender and class) as well as familial and community resources. In this article, we examine the cross-national research on educational gaps, examining the inequalities between children of immigrant descent from those of native origin. Secondly, we specifically examine the gender gaps literature among immigrant children and their native counterparts with special attention to micro, meso and macro level factors. Finally, we offer a potential research agenda to examine these processes at multiple levels of analyses.

In sum, the main questions guiding this literature review are: What is the role of the host societies' institutional educational structures (aimed at integrating migrant youth)? Are these institutional efforts affecting male and female children of migrants differently? Do institutional educational structures at the country level have an impact on gender gaps in educational outcomes? Specifically, what is the role of socialization at home and in schools? Do migrant girls experience a different pattern of acculturation /integration in educational settings compared to their male 
counterparts depending on their family structure? What is the role of student's social and familial background in explaining these differences?

Immigrants-native educational outcome gaps

Several studies seek to explain immigrant-native gaps in downward assimilation. The seminal work on segmented assimilation by Portes and Rumbaut (2006) established the proposition that children of poorly educated and working-class immigrants are more likely to experience downward assimilation (see also Portes and Zhou 1995). Waldinger and Feliciano (2004) show slightly more optimism in terms of labor participation for the second generation vis-à-vis natives, especially for women. They show how second generation Mexican-American women have higher labor participation rates than MexicanAmerican men and closer to the rates among native whites. Both studies emphasize the importance of the context of reception, such as the safety levels of immigrant neighborhoods and quality of inner city schools to explain future modes of adaptation (Waldinger and Feliciano 2004). In the US, different patterns of assimilation across groups can thus be explained as a function of race, ethnicity and socioeconomic background as well as geographic location (e.g. the existence of an ethnic enclave and type of school district). Moreover, by segmentation, this literature attempts to capture the differences across types of migrants (nationalities, economic migrants, political refugees etc), and also different types of intergenerational parental relationships which often develop into what Portes and Rumbaut (2006) characterized as consonant and dissonant acculturation.

As mentioned by several scholars however, the heterogeneity of adaptation is due to characteristics and values of immigrants before emigrating as well as the contexts of reception in the host society (Vaquera and Kao 2012: 1562). As documented extensively in the US based literature, while some children tend to have educational difficulties while adapting to new environments, other immigrant youth outperform their native counterparts. This research is often focused on the 
educational backgrounds of parents vis-à-vis their children, the importance of parental involvement for academic success (see Jeynes 2001; Epstein 2001), their uneven linguistic incorporation among the members of an immigrant household (Van de Werfhorst 2010) and the educational expectations of their parents and the children themselves (Vaquera and Kao 2012; see also Kao and Tienda 1995, Bauer and Riphahn 2007).

Research on educational outcomes has further established the distinction between aspirations and actual performance (Kao and Tienda 1995, see Salikutluk 2013 for a review of this literature). This is commonly referred to as the immigrant's aspiration paradox, the idea that immigrants are more optimistic than non-migrants about the benefits of achieving high levels of education (Kao and Tienda 1995; Levels et al., 2008; Salikutluk 2013). Such optimism is often due to unrealistic expectations of parents and students themselves about the actual opportunities offered by the educational systems and labor market opportunities in the host society (Kao and Tienda 1995, Salikutluk 2013). Others argue that migrant families' emphasis on achieving higher education, is not only a response to the perceived and actual discrimination experienced but also the lack of opportunities in the labor market for minorities (Sakikutluk 2013). Some studies show that disadvantages among some second generation students persist through the educational system although some eventually gain educational credentials with pay off in the job market (Alba, Sloan and Sperling 2011; Heath et al 2008; Crul and Holdaway 2009).

With regard to actual performance, the empirical evidence of migrant youth underperformance vis-à-vis natives is quite compelling. Students from disadvantaged homes are more likely to drop out from the educational systems without gaining a final credential (Alba and Silberman 2009; see also Telles and Ortiz 2008). Using PISA data, one study shows that in 2003, on average, among 17 OCED countries, migrant youth scored more than one school year behind their native counterparts in mathematics (see OCED 2005). As pointed out in this study however, these results varied greatly across 
countries (OECD 2005). For example, among the first generation there was more than a 90 score point difference in math achievement between Belgium and Sweden. Similarly, the report shows significant country differences across math achievement among the second generation. Similarly, Alba et al. using PISA show that in terms of literacy native students (in the EU countries, Sweden, The Netherlands, Great Britain, Germany and France) score on average between 505 to 520, while the second generation score on average 50 points less (with the largest difference being in Germany) (se Alba, Sloan and Sperling 2011: 398). These authors however acknowledge that the native/second generation gap would be much smaller if the comparison was established between parents of equal educational levels, although significant differences persist (Buchmann and Parado 2006; Alba, Sloan and Sperling 2011). Overall, trends show however that despite some noticeable native/immigrant gaps and inequalities (especially among families of low socioeconomic status), the second generation tends to outperform their parent's in terms of levels of education. Also, in some instances and for some specific groups they might outperform some native populations.

The emphasis on contextual characteristics and their effects on educational outcomes among the second generation have also included inequalities occurring in school settings (Suarez-Orozco and Suarez-Orozco 2001). Portes and Hao (2004), show how the ethnic composition of the classroom, (for example, the presence of a greater number of co-ethnics) acts as a leveling mechanism, transforming schools into less intimidating and competitive environments for immigrant children. Thus, in their study, more competitive school environments seem to be relevant for the Mexican-origin students, who are more likely to drop out when enrolled in schools with a student population of higher SES (and less coethnic peers), in comparison to other immigrant-origin students (e.g. Vietnamese, Korean and Chinese). Other research, also emphasizing social context, examines the role that the school's climate and students' social networks play in the academic success of immigrant children (Suarez-Orozco and Suarez-Orozco 2001; see also Vaquera and Kao 2012). The importance of social capital in and outside 
the family is thought to be critical among immigrant youth, as significant others (parents, teachers and peers) act as role models and shape children's attitudes and behaviors (see Suarez-Orozco and Suarez Orozco 2011). We now turn to examine the research that examines the gender gaps.

\section{Gender gaps in educational outcomes}

Families, schools, communities and policies play a role in explaining gender gaps in different dimensions of educational performance, specifically among first and second generation migrant youth. From the immigration and education literature, research shows that female migrants outperform their male counterparts in grades and educational ambition (Zhou and Bankston 2000). Figure 1 shows PISA data on the percentage of second generation migrants and native students who have repeated a school grade, by gender. The overall trend shows how girls are less likely to repeat a grade than boys with substantial differences in Belgium, France and Spain among native and immigrant students. The potential explanations for such differences in educational settings, points in different directions.

\section{***Figure 1 about here ${ }^{* * *}$}

The extant literature in the U.S has documented that, on average, parents tend to be more involved with girls than with boys, especially as they grew older (Stevenson and Baker 1987). This may account for gender gaps in achievement in some instances, but studies that address the impact of parental involvement fail to find consistent associations across the board (Muller 1998). This notwithstanding, analyses show that parental involvement plays a role in more subtle and indirect ways. Thus, Entwisle et al. (2005) find that educational expectations of parents favor girls among low income families. As a result lower-class boys are more likely to be less academically-oriented.

Active parental involvement in homework and daily extracurricular activities, conferences with teachers but also involvement at the policymaking level is thought to be key for children's success 
(Epstein 1995, 2001). Immigrant families however often face more difficulties engaging in such activities due to language difficulties or immigrant parents' cultural expectations about the value of education (Suarez-Orozco and Suarez-Orozco 2001). Some gender discrimination experienced by second generation girls is deeply rooted in their cultural background and the gender norms parents transported from the country of origin. The trend in many cases is to favor boys, especially in sending communities and among families living, particularly, in rural areas (Knowg 2000). But are these trends reproduced among immigrant families in the host society? Qualitative research shows that there are no (or limited) differences in parental educational expectations (Qin 2006). Immigrant families are as likely to send both daughters and sons to school. Some ethnographic studies show that immigrants' parents are usually stricter with their daughters than with sons (Espiritu 2009; Gibson 1988; Lee 2001, Sarroub 2001), and hence may demand better performance in school. Feliciano and Rimbaut argue that it is often the maintenance of traditional gender roles in home that pushes girls to succeed academically and pursue educational and occupational ambitions that are non-traditionally gendered (2005: 1092). Studies on Vietnamese and Filipino second generation girls have examined the socialization processes occurring at home and how parental supervision is key in understanding not only girls' educational performance but also feelings of dissatisfaction for unfulfilled aspirations because of such parental supervision (Zhou and Bankston 2001; Wolf 2006; Espiritu and Tran 2006). Smith (1999) describes similar patterns among Mexican groups in New York. Migrant girls see school as a "liberating social space" because it is free from parental monitoring (Olsen 1997) and develop an instrumental view of education as "empowerment against tradition" (Keaton 1999).

Some scholars have examined the negative aspects of socialization of masculinity, arguing that such practices help explain underperformance in the educational system (Buchanan, DiPrete and McDaniel 2008). Research focused on socialization processes at school shows that second generation girls are more likely to have friends who are more serious about schoolwork and supportive of academic 
achievement (Hamm and Faircloth 2005). In contrast, boys are more likely to experience discrimination and be subject of bullying. Gang activities are often a response to these experiences (Lundy and Firebaugh 2005). Legewie and DiPrete (2012) argue that lower quality schools foster - or at least do not inhibit-development of a peer culture that constructs resistance to schools and teachers as valued masculine traits, and denigrates academic achievement. Girls' peer groups, by contrast, vary less strongly with the social environment to the extent that pro-school attitudes are stigmatized as unfeminine. As a result, boys, in particular, gain more than girls from school resources that sustain an academically-oriented environment (better facilities, better curriculum, better teachers, and better support staff), and the size of the gender gap in educational performance depends on factors connected to the quality of schools. Although Legewie and DiPrete's analysis does not address explicitly gender gaps among students of different ethnic background, their research is potentially very relevant in accounting for gender gaps in highly segregated school systems, where ethnic minorities are often confined to low quality environments.

Some males may also experience frustration as they witness the success of their female counterparts or experience reverse sexism that hurts boys as classrooms are "remodeled to serve the needs of girls. Less structured learning environments and less focus on grades and competition are hallmarks of a changing school landscape that put boys at a disadvantage" (Sommers in Roe Garrett 2011). A lack of male role models, scarcity of male teachers, and fundamental economic transformations in the economy (e.g. feminization of the labor market) are some of the alternative explanations for the gender gap in educational achievement.

Along similar lines, research focused on identity formation processes (see Portes and Rumbaut 2006), emphasize that there is selective acculturation, which combines rapid economic mobility with preservation of immigrant community solidarity and culture. However, segmented assimilation theory has not always given gender its due attention. As indicated by López (2003: 5) "a real weakness of 
segmented assimilation theory is that its central analytical category-assimilation-neglects the fact that the very social networks, neighborhood, schools, job opportunities, and family arrangements that are open to the second generation are racialized and gendered"- Gender represents an important structuring and organizing principle of every day life for immigrant children. It embodies norms and practices to which the immigrant child is expected to adapt in the new cultural context. These norms and practices channel immigrant children into gendered pathways that shape gendered educational outcomes and prospects for social mobility, where men most of the time lag behind women (Feliciano \& Rumbaut 2005; Quin 2004, 2006). Some argue that girls are more equipped to develop a bicultural identity and that leads to a better adaptation (Heath and Mclaughlin 1993). Thus, girls are more likely to develop a "hyphenated identity" and are less likely to develop "oppositional culture" (Lundy and Firebaugh 2005). López (2003) finds that girls in migrant Caribbean families in New York are socialized in the need to become financially independent in order not to depend on men to support them, and this encourages them to perform well at school.

Finally, key in the development of these identities and attitudes towards schooling is the role that communities play in providing resources such as mentoring services for ethnic peers (Alba, Sloan and Sperling 2011; Crul 2002). In the US, the work by Zhou (2009) shows the importance of social networks and community based resources such as ethnic newspapers as key informational resources for Asian families regarding the educational system (Zhou and Kim 2001). Others show how for the Latin American communities these resources are weaker and less available (Portes and Rumbaut 2006). All these perspectives however, have predominantly focused on individual (micro) level attributes or school, parental and community characteristics (meso). Less attention has been given however, to more institutional educational structures (e.g. existence or not of tracking systems, systemic intercultural and bilingual education programs) and how these structures trickle down and affect the integration of migrant youth in schools but also their transition to the labor market. While there is a great deal of 
research examining gender and achievement focused on the effects of family status, children's ambitions and self-esteem, and the role of the school setting/climate, less research has been conducted in explaining how macro-institutional educational structures affect gender gaps in education.

Institutional educational structures and gender gaps.

There is an extensive literature focusing on the effects of institutional characteristics on different outcomes related to immigrant's socio-economic integration (Lewin-Epstein et al. 2003); examining the effects of integration policies on immigrants' overall levels of assimilation (Koopmans 2010) and assessing the effects of policies on immigrants' employment rates (Kesler 2006; Kogan 2006; Van Tubergen et al. 2004). We argue that several factors related to a country's institutional educational structure trickles down to the individual level and affects immigrant children's social integration at the school level. The segmented nature of migrants' adaptation processes are influenced by institutional variation and differential access to the labor market across welfare state regimes. But are these welfare state regimes gender neutral for immigrant youth? We argue that research is needed to examine how specific educational policy resources directed to the integration of migrant youth (e.g. the existence of teacher's training, language courses, policies fostering parents' involvement, and enrollment in intercultural extra-curricular activities, etc.) affect girls and boys differently. The results would inform both discussions of integration models in countries of recent immigration and research on gender differentials in educational performance.

Some research also shows that educational tracking systems based on differentiating students by type of credential (vocational track versus non vocational tracks) lead not only to a range of credentials with different value in the labor force but also shows disparities across ethnic groups and across students with different social backgrounds (Alba, Sloan and Sperling 2011; Van der Werfhorst and Mijs 2010). Systems that define tracks early, based on a student's age (such as in the case of German) 
might produce a disadvantage for immigrant students vis-a -vis those systems that start later or do not have a tracking system at all (Alba, Sloan and Sperling 2011; see also Crul and Schenider 2009). Immigrant students seem to need more time than native students to demonstrate their ability (Alba, Sloan and Sperling 2011; Pásztor 2009) and often lack the social capital and the parental guidance to succeed in a system that differentiate students early. Other educational systems without tracking rely on grades or whether students have taken advance placement classes to classify and channel students' educational trajectories. In the US, the evidence seemed to suggest that Latino students tend to take fewer advance placement classes than Asian and white students (Conger et al. 2009). There is no systematic research that examines whether more formal educational tracking systems versus more internal systems such the one in the US or Sweden produce greater gender gaps between vocational and non-vocational careers and in their transitions to the workforce.

In addition to these institutional features of educational systems, other types of national policies might affect educational outcomes across gender lines. For example in the US school funding systems and residential segregation are of critical importance in explaining inequalities of educational outcomes across different ethnic groups (see Alba and Silberman 2009). Moreover, in a recent study examining the effect of national policies on 'adolescent reading literacy' the results show a strong association between inequality and educational outcomes (see Siddiqi et al. 2012). Using multilevel techniques, in which students are nested in schools and the later into country institutional structures, Siddiqi and colleagues show, that while levels of educational spending and overall economic prosperity do not directly explain reading literacy, overall income inequality levels exhibited a strong association. Thus higher levels of income inequality yielded lower levels of reading literacy among adolescents. Similarly, Hillmert (2013) in an empirical study using MIPEX data, shows that specific national contexts determine the educational outcome of migrants. He argues that a combination of macro-level conditions (such as educational policies; and patterns of migration); and micro level conditions (the performance of migrants within the 
national education systems) are key to assess migrants' overall educational performance. His findings show that while a significant part of the relative disadvantage can be explained by a combination of social composition of migrants and general patterns of social inequality in education, in some cases significant differences remain even when controlling for such group differences. Hillmert emphasizes the role that institutions and immigration policies as well as integration and educational policies have in determining the situation of migrants with regards to education. But once again, less examined are the effects of inequality from a gendered perspective. Are these national educational policies and levels of social inequality creating gender imbalances? Are girls benefiting more than boys from systems with highly centralized funding schemes versus those that are less decentralized? In the last section of the paper we specifically propose a series of research questions focusing on processes occurring at the macro, meso and micro levels (and their interactions) to examine such differences cross-nationally.

\section{Conclusion and discussion}

We started this paper emphasizing the importance of establishing a theoretical distinction of multiple level effects in explaining educational outcomes in terms of gender gaps among immigrant youth. We have argued that gender represents a central tenet, a structuring and organizing principle to understand immigrant children processes of adaptation. Gendered pathways shape educational outcomes and prospects for social advancement and in these trajectories, there is strong evidence that men, most of the time, seem to lag behind women. While some research points in the direction of improving school resources to reduce gender gaps, others emphasize the need for better role models for men. Other research places emphasis on the importance of peer groups and community resources and how schools often become liberating social spaces for girls, especially after taking into account the importance of families cultural background, for example as it relates to parent's educational aspirations. Others argue that girls are more equipped to develop a bicultural identity are more likely to develop a 
hyphenated identity and thus are less likely to develop oppositional culture in school settings. We have argued that there is not a systematic analysis of how these processes (for example the role of parent's cultural background) reproduces gender gaps in a comparative framework across different host societies. Cross-national research in particular has not been able to tap into on how norms, values, and practices travel across borders. Are these parents importing their educational aspirations from the countries of origin and reproducing them in the host society? How do these beliefs and aspirations change as these families interact with community resources at schools located in ethnic enclaves? We believe that answers to these questions can not only inform and aid policymakers in the area of education, but are an epistemic priority.

Moreover, while national educational systems matter in gaps between immigrants and native students, their gender implications are less obvious. For example, early tracking systems seem to place immigrant families at a disadvantage but do these systems affect girls and boys equally? Similarly, are school systems with very decentralized funding systems accentuating gender gaps among immigrant students than systems with more nationally, centralized school funding schemes? And more broadly, are overall levels of social inequality and their impacts on educational outcomes gender-neutral? Crossnational research examining gender gaps on different educational outcomes can shed light on these processes as mutiple group comparisons can be established across different institutional environments. Similarly, is the socialization at school affected by these larger policies and institutional frameworks? For example bullying and gang violence, a known fact related to the underperformance of boys, especially among members of a minority group might be mitigated or reduced in school systems where parental involvement is not only encouraged (e.g. based on being engaged in home school activities) but where immigrant parents are involved in the decision-making structures of the schools. Overall, we argue that all these macro and meso level processes related to educational institutional environments in interaction with student level characteristics are key in explaining the inequalities across gender lines. 
Figure 1.Percentage of Second generation migrant and non-migrant students repeating a school grade, by gender.

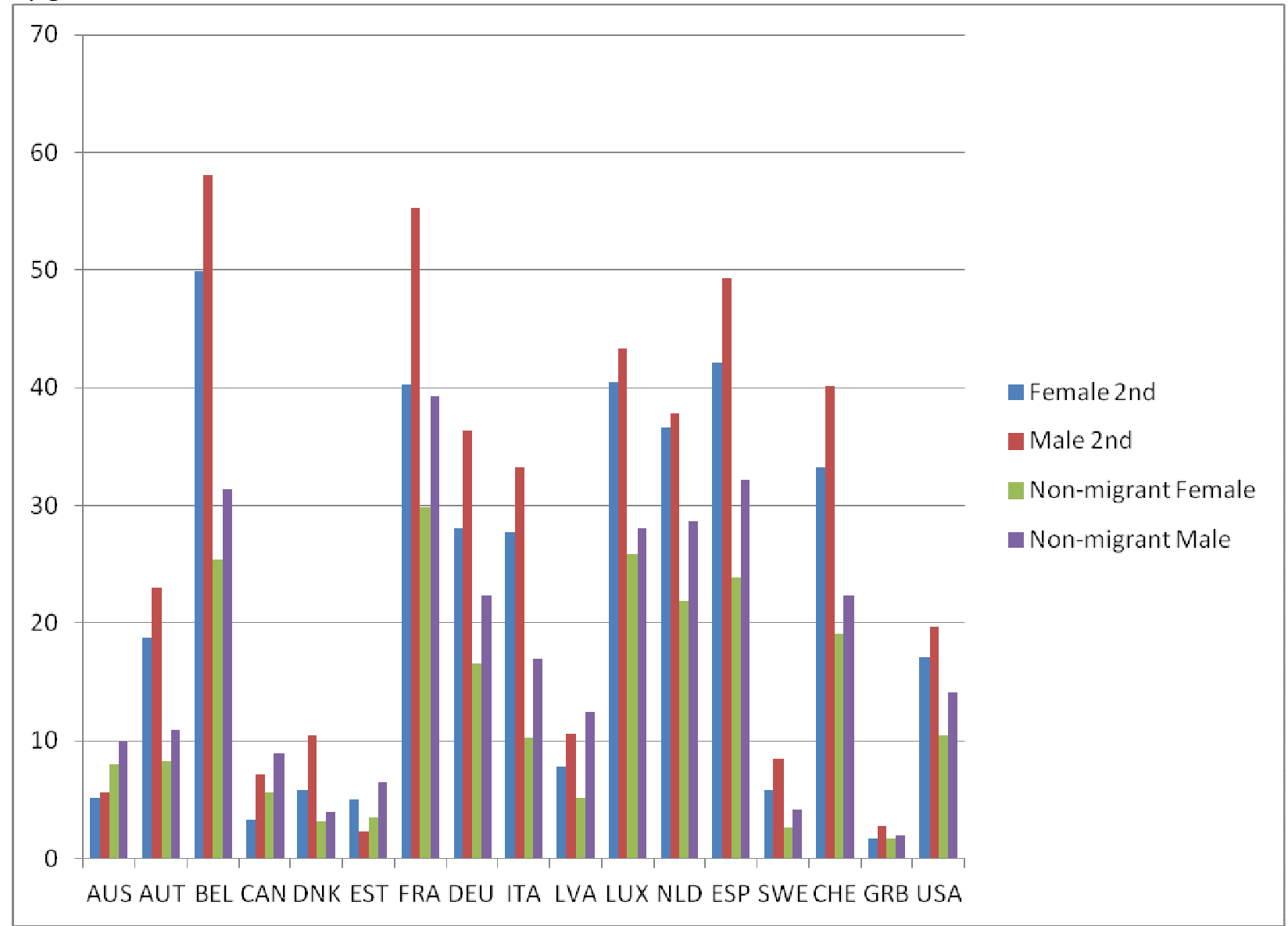

\section{References:}

Alba, R., Sloan, J. and Sperling, J. 2011. 'The integration imperative: The children of low-status immigrants in the schools of wealthy societies', Annual Review of Sociology, 37: 395-415.

Alba, R. and Silberman, R. 2009. 'The children of immigrants an host-society educational systems:

Mexicans in the U.S. and North Africans in France. Teachers College Record, 111: 1444-75.

Bauer and Riphahn 2007. 'Heterogeneity in the intergeneretional transmission of educational attaintment: evidence from Switzerland on natives and second generation immigrants", Population Economics, 46:209-37. 
Buchanan, C., DiPrete, T. and McDaniel, A. 2008. 'Gender inequalities in education', Annual Review of Sociology 34: 319-337.

Buchanan, C. and Parrado, E. 2006, 'Educational achievement of immigrant-origin and native students: a comparative analysis informed by institutional theory', International perspectives on education and society, 7: 345-77.

Bell, N.F and Blanchflower, D. G., 2011, 'Youth Unemployment in Europe and the United States', working paper, IZA DP no. 5673, Institutite for the study of labor.

Conger, H, Long, M.C. latarola P. 2009, 'Explaining race, poverty and gender disparities in advanced course-taking', Policy Analysis and Management, 28(4): 555-76.

Crul, M. and J. Holdaway. 2009, 'Children of Turkish Immigrants in Germany and the Netherlands: The impact of differences in vocational and academic tracking systems', Teachers College Record, 111: 1476507.

Crul, M. and Vermuelen, H. 2003, 'The second generation in Europe', International Migration Review, 37(4): 965-986.

DeVellis, R.F. 1991, Scale development. Newbury Park, NJ: Sage Publications

Entwisle, D. R., Alexander, K. L., \& Olson, L. S. 2005, 'First grade and educational attainment by age 22: A new story', American Journal of Sociology, 110(5): 1458-1502.

Epstein, J. 2001, School, Family, and Community Partnerships: Preparing Educators and Improving Schools. Boulder, CO: Westview.

Espiritu, L.Y. and Tran T., 2006 'Vietmam my country: Vietnamese Americans and Transnationalism” in Peggy Levitt and Mary C. Waters, The Changing Face of Home: Transnational Lifes of the Second Generation', Russell Sage Foundation; pp. 367-399

Esser, H., 2006, Migratio, Language and Integration, AKI Working Paper. Programme on Intercultural Conflicts and Societal Integration. 
Feliciano, C. and Rumbaut, R. 2005. Gendered paths: Educational and occupational expectations and outcomes among adult children of immigrants. Ethnic and Racial Studies 28 (6): 1087-1118.

Fleishmann, and Dronkers, 2010 “Unemployment among immigrants in European labor markets:

Analysis of origin and destination effects", Work, Employment and Society; 24: 337-54.

Freeman, G P.1995, "modes of immigration politics in liberal democratic states", International Migration Review,29, pp. 881-902.

Garret, Rose, 2011 “Gender Gap: why boys can't keep up”, in education.com http://www.education.com/magazine/article/the-gender-gap/

Gibson, M. A. 1988. Accommodation without assimilation: Sikh immigrants in an American high school. Ithaca, NY: Cornell University Press.

Guiso, L., F. Monte, P. Sapienza, L. Zingales (2008) “Culture, gender and math”, Science: pp. 1164-1165.

Heath, SB and Mclaughlin, M.W., 1993, Identity and Inner city youth: Beyond Ethnicity and gender, Teachers College Press.

Heath, A.F., Rothon, C. and Kilpin, E. 2008, "The second generation in Western Europe: Education, Unemployment and Occupational Attainment", Annual Review of Sociology 34: 211-35.

Heath, A. F., 2007 'Cross-National Patterns and Processes of Ethnic Disadvantage', pp. 639-695 in Heath, A. and Cheung, S. Unequal Chances: Ethnic Minorities in Western Labor Markets, Proceedings of the British Academy, Oxford: Oxford University Press.

Hillmert, S. 2013, "Links between immigration and social inequality in education: A comparison among five European countries", Research in Social Stratification and Mobility, 23: 7-23.

Jeynes, W.H. 2005, 'Effects of parental Involvement and family structure on the academic achievement of adolescents', Marriage and Family Review, 37(3): 99-116. 
Kao, G and Tienda, M, 1995 “Optimism and Achivement: The educational performance of immigrant youth", Social Science Quarterly, 76(1): 1-19.

Keaton, T. 1999. "Muslim Girls and the "other France": An examination of identity construction. Social" Identities 5(1): 47-64.

Kesler, C. (2006) 'Social Policy and Immigrant Joblessness in Britain, Germany, and Sweden', Social Forces, 85(2), 743-770.

Kogan, I. (2006) 'Labor Market and Economic Incorporation among Recent Immigrants in Europe', Social Forces, 85(2), 697-722.

2003, 'Ex-Yugoslavs in the Austrian and Swedish Labour Markets: The Significance of the Period of Migration and the Effect of Citizenship Acquisition', Journal of Ethnic and Migration Studies, 29(4), 595-622.

Koopmans, R. (2010) 'Trade-Offs between Equality and Difference: Immigrant Integration, Multiculturalism and the Welfare State in Cross-National Perspective', Journal of Ethnic and Migration Studies, 36(1): 1-26.

Koopmans, R., Stratham, P., Giugni, M. and Passy, F. (2005) Contested Citizenship: Immigration and Cultural Diversity in Europe. Minneapolis, MN: University of Minnesota Press.

Kwong, J., 2000, The dilemma in Chinese women's receiving an education. Chinese Education and Society, 33(2): 37-43.

Lahav, G. (2004) Immigration and Politics in the New Europe: Reinventing Borders, Cambridge and New York: Cambridge University Press.

Lee, S. 2001. Exploring and transforming the landscape of gender and sexuality: Hmong American teenaged girls. Race, Gender \& Class 8(1), 35-46. 
Lewin-Epstein, N., Semyonov, M., Kogan, I. and Wanner, R. 2003 'Institutional Structure and Immigrant Integration: A Comparative Study of Immigrants' Labor Market Attainment in Canada and Israel', International Migration Review, 37(2), 389-420.

Legewie, J, and DiPrete, T. 2012, School Context and the Gender Gap in Educational Achievement", American Sociological Review 77 (3): 463-485 .

Levels, M, Dronkers, J., Kraaykamp, G. 2008, 'Immigrant children 's educational achievement in western countries: origin, destination, and community effects on mathematical performance', American Sociological Review, 73: 835-53.

López, N. (2003). Hopeful Girls, Troubled Boys: Race and Gender Disparity in Urban Education. Nueva York: Routledge.

Lundy, G.F, and Firebaugh, G., 2005, “Peer relations and school resistance: Does oppositional culture apply to race or to gender? Journal of Negro Education 74(3): 233-45.

Marks, G.N., 2005, Accounting for immigrant and non-immigrant differences in reading and mathematics in twenty countries, Ethnic and Racial Studies, 28: 925-46.

Mark, L. and Dronkers J., 2008, Educational performance of native and immigrant children from various countries of origin", Ethnic and Racial Studies, 31(8): 1404-1425.

Messina, A. 2007 The Logics and Politics of Post-WWII Migration to Western Europe. New York: Cambridge University Press

Migrant Integration Policy Index. 2011 Dataset generated by the British Council and the Migrant Policy Group, accessed in September 2011: www.mipex.eu

Muller, Ch. 1998 “Gender differences in parental involvement and adolescents' mathematics achievement" Sociology of Education 71(4): 336-356.

Olsen, L. 1997. Made in America: Immigrant students in our public schools. NY: The New York Press. Salikutluk Z., 2013 “Immigrant’s aspiration paradox”, Working paper, Universitat Mannheim. 
OECD, 2005 Programme for International Student Assessment 'Where Immigrant Students Succeed: A Comparative Review of Performance and Engagement in PISA 2003'. OECD publications.

Suarez-Orozco, C. and Suarez-Orozco, M. 2001, Children of Immigration. Cambridge, MA: Harvard University Press.

Pásztor, A. 2009, 'Different seettings, different choosers? Applying Ball's framework on the case of second generation Turks', International Studies in Sociology of Education, 19(3-4): 203-15.

Portes, A. and Hao, L. 2004, 'The schooling of children of immigrants: Contetxual effects on the educational attainment of the second generation'. Proceedings of the National Academy of Sciences of the United States of America, 101(33): 11920-927. www.pnas.org.

Portes, A. and Rumbaut, R, 2006, Immigrant America. Berkeley University of California Press. $3^{\text {RD }}$ edition. Portes, A. and Zhou, M., 1995, 'The new second generation: segmented assimilation and its variants', Annals of the American Academy of Political and Social Science, 530: 74-96.

Quin, D. B. 2004. Understanding the role of gender in Chinese immigrant students' educational and psychosocial adaptation. Unpublished doctoral dissertation, Harvard University Graduate School of Education, Cambridge, MA.

Quin, D. B. 2006 'The role of gender in immigrant children's educational adaptation', Current Issues in Comparative Education 9 (1): 8-19.

Reitz, J. 1998, Warmth of the Welcome: The Social Causes of Economic Success for Immigrants in Different Nations and Cities, Boulder, CO: Westview Press

Siddiqi A, Kawachi I., Berkman L., Hertzman C., and Subramanian S.V. 2012, 'Education determines a nation's health, but what determines educational outcomes? A cross-national comparative analysis', Journal of Public Health Policy, 22(1): 1-15.

Sarroub, L., K. 2001. The sojourner experience of Yemeni American high school students: An ethnographic portrait. Harvard Educational Review 71(3): 390-415. 
Smith, R. 1999. The education and work mobility of second-generation Mexican Americans in New York:

Preliminary reflections on the role of gender, ethnicity and social structure. Paper presented at the Eastern Sociological Society meeting. Boston

Stevenson, D. L. and Baker, D. P. 1987. "The family-school relation and the child's school performance" Child Development 58 (5): 1348-1357.

Telles, E. and Ortiz, V. 2008 Generations of Exclusion: Mexican Americans, Assimilation, and Race. New York: Russell Sage Foundation.

Waldinger, R. and Feliciano C. 2004, 'Will the new second generation experience 'downward assimilation'? Segmented assimilation re-assessed', Ethnic and Racial Studies, 27(3): 376-402.

Wolf, L.D. 2006 'There's no place like 'home': Emotional Transnationalism and the struggles of second generation Filipinos" in Peggy Levitt and Mary C. Waters, The Changing Face of Home: Transnational Lives of the Second Generation', Russell Sage Foundation; pp. 255-295.

Joppke, C. and Morawska, E, 2003, Toward Assimilation and Citizenship Immigrants in Liberal NationStates Basingstoke: Palgrave Macmillan 256.

Van Tubergen, F., Maas, I. and Flap, H. 2004, 'The Economic Incorporation of Immigrants in 18 Western Societies: Origin, Destination, and Community Effects', American Sociological Review, 69(5), 704-727. Vaquera, E. and Kao, G. 2012, 'Educational Achievement of Immigrant Adolescent in Spain: Do Gender and Region of Origin Matter?', Child Development, 83(5): 1560-1576.

Van de Werfhorst, G. H., and Mijs, Jonathan J.B. 2010, 'Achievement inequality and the institutional structure of educational systems: A comparative perspective', Annual Review of Sociology, 36:407-28. Zhou, Min and Carl L. Bankston, III. 2000, Straddling Different Social Worlds: The Experience of Vietnamese Refugee Children in the United State. New York: ERIC Clearinghouse on Urban Education, Institute for Urban and Minority Education, Teachers College, Columbia University.

Zhou, M. and Bankston, C. L. 2001, 'Family pressure and the educational experience of the daughters of 
Vietnamese refugees', International Migration 39(4): 133-151.

1

2

3

4

5

6

7

8

9

10

11

12

13

14

15

16

17

18

19

20

21

22

23

24

25

26

27

28

29

30

31

32

33

34

35

36

37

38

39

40

41

42

43

44

45

46

47

48

49

50

51

52

53

54

55

56

57

58

59

60 